\title{
ALFABETIZAÇÃO FINANCEIRA: MENSURAÇÃO DO COMPORTAMENTO E CONHECIMENTO FINANCEIROS DOS UNIVERSITÁRIOS DA UNIVERSIDADE DA REGIÃO DA CAMPANHA, RIO GRANDE DO SUL
}

\author{
FINANCIAL LITERACY: THE MEASUREMENT OF THE FINANCIAL BE- \\ HAVIOR AND THE FINANCIAL KNOWLEDGE OF THE STUDENTS OF \\ UNIVERSIDADE DA REGIÃO DA CAMPANHA, RIO GRANDE DO SUL
}

\author{
Suelen Seixas Azambuja Jobim ${ }^{1}$ E Vanderleia Leal Losekann ${ }^{2}$
}

Recebido em: 17/07/2015 Aprovado em: 15/12/2015

\section{RESUMO}

Esse estudo teve como objetivo identificar o nível de alfabetização financeira dos estudantes universitários pertencentes à Universidade da Região da Campanha (URCAMP), localizada em São Gabriel, Rio Grande do Sul, por meio da mensuração do comportamento e conhecimento financeiros. Para tanto, foram aplicados 126 questionários aos estudantes concluintes dos cursos de Administração, Direito, Ciências Contábeis e Educação Física e foram utilizados o comportamento e o conhecimento financeiros como proxies da alfabetização financeira. Para avaliar o comportamento financeiro, foi realizada uma Análise Fatorial Exploratória (AFE), que revelou quatro fatores: investimento e poupança, gestão financeira pessoal, consumo planejado e utilização do crédito. $\mathrm{Na}$ sequência, analisou-se o conhecimento financeiro dos universitários com base no acerto das questões respondidas. Os estudantes foram classificados, com base na pontuação obtida nas questões de conhecimento financeiro, em: alto, mediano ou baixo desempenho. Por fim, concluiu-se que os estudantes universitários da URCAMP, de modo geral, apresentam um nível mediano de alfabetização financeira, indicando a necessidade de desenvolver ações voltadas ao conhecimento financeiro, não apenas no nível superior, mas desde a base do processo educacional.

Palavras-chave: Alfabetização financeira; Conhecimento financeiro; Comportamento financeiro.

\begin{abstract}
The aim of this study was to identify the level of financial literacy of the university students from Universidade da Região da Campanha (URCAMP), located in São Gabriel, Rio Grande do Sul, through the measurement of their financial behavior and knowledge. For this, 126 questionnaires were applied to the final-semester students from the Business Administration, Law, Accounting Sciences and Physical Education courses. The behavior and financial knowledge were used as proxies of the financial literacy. To assess the financial behavior, an Exploratory Factor Analysis (EFA) was used. The EFA revealed four factors: savings and investment, personal financial management, planned spending and use of credit. Following, the university students' financial knowledge was analyzed based on the correct answers. The students were classified based on the performance in the financial knowledge questions according to the punctuation obtained in: high, average or low performance. Lastly, it was concluded that the university students from URCAMP, in general, show an average level of financial literacy indicating the necessity of development of actions aimed at the financial knowledge, not only in the higher education level, but also since the beginning of the educational process. Keywords: Financial literacy; Financial knowledge; Financial behavior.
\end{abstract}

'Especialista em Gestão de Finanças e da Informação pela Faculdade Palotina de Santa Maria (FAPAS), Brasil. Professora Do curso Técnico em Administração na Escola Estadual XV de Novembro, São Gabriel. E-mail: suelenjobim@outlook.com.br. ufsm.br. 


\section{Introdução}

A evolução do mercado financeiro nacional trouxe novos desafios a serem enfrentados, uma vez que ampliou a variedade de produtos e serviços financeiros, exigindo mais conhecimento na hora de buscar dinheiro e/ou investi-lo. Logo, para exercer a cidadania, o indivíduo deve saber lidar com questões relacionadas à sua renda, à gestão do seu dinheiro, aos gastos, aos empréstimos, à poupança e aos investimentos em curto e longo prazo (MATTA, 2007). Além disso, "o cidadão educado financeiramente reflete sobre o próprio consumo e seus impactos econômicos, sociais e ambientais com maior propriedade" (BRASIL, 2014, p. 4).

Contudo, esse exercício de cidadania em relação às finanças pessoais nem sempre se delineou por esse ângulo, haja vista a conjuntura econômica desfavorável, marcada por altas taxas de inflação e pelo incentivo maciço à cultura do consumo imediato, a que os brasileiros foram submetidos na década de 80 (BRESSER-PEREIRA, 2003). Apenas recentemente temas como alfabetização financeira, educação financeira, gestão financeira pessoal, aposentadoria e utilização responsável do crédito estão sendo tratados com a devida relevância no Brasil por meio de políticas públicas e de estudos relacionados ao tema.

A alfabetização financeira também pode ser vista sob a perspectiva do bem-estar pessoal, sendo importante para evitar consequências que vão desde a desorganização das contas domésticas até a inclusão do nome em sistemas como o Serviço de Proteção ao Crédito (SPC) e o Serasa Experian, que prejudicam não só o consumo, mas também, em muitos casos, a carreira profissional (LUCCI et al., 2006).

Em relação aos termos educação financeira e alfabetização financeira, poucos foram os autores que tentaram diferenciá-los. De modo geral, a principal diferença está no enfoque dado, uma vez que a educação financeira enfatiza o conhecimento e que a alfabetização financeira envolve, além do conhecimento, a habilidade, o comportamento e a atitude financeira dos indivíduos (PARABONI et al., 2013; POTRICH et al., 2013).

Tendo em vista a relevância do tema e os poucos estudos relacionados à alfabetização financeira no Brasil, tornase necessário o desenvolvimento de pesquisas que busquem discutir e analisar o assunto. Dessa forma, esta pesquisa foi realizada no âmbito da Universidade da Região da Campanha (URCAMP), localizada na cidade de São Gabriel, Rio Grande do Sul, com o intuito de estudar o nível de alfabetização financeira dessa população. Para tanto, elenca-se o seguinte problema de pesquisa: qual o nível de alfabetização financeira dos estudantes universitários pertencentes à URCAMP de São Gabriel?

Para responder o problema de pesquisa, formulou-se o seguinte objetivo geral: identificar o nível de alfabetização financeira dos estudantes universitários pertencentes à URCAMP - campus de São Gabriel, por meio da mensuração do comportamento e conhecimento financeiros. Já os objetivos específicos são: mensurar o comportamento financeiro e avaliar o conhecimento financeiro dos estudantes universitários da URCAMP de São Gabriel.

Com base nos objetivos propostos, o trabalho está estruturado em cinco seções, incluindo a introdução. A segunda seção apresenta o referencial teórico, com foco nos tópicos definidos para o trabalho; na terceira seção, são apresentados os procedimentos metodológicos adotados nesta pesquisa; na quarta seção, encontram-se a análise e discussão dos resultados; por último, são expostas as considerações mais relevantes acerca do estudo realizado, bem como as limitações e sugestões para pesquisas futuras. 


\section{Referencial teórico}

\subsection{Alfabetização financeira}

De acordo com Donadio e colaboradores (2012), embora o termo alfabetização financeira seja frequentemente utilizado como sinônimo de educação financeira ou conhecimento financeiro e poucos tenham sido os pesquisadores que tentaram diferenciar esses termos, é possível verificar que a alfabetização financeira vai além da ideia básica de educação financeira.

Segundo a Organização para Cooperação e Desenvolvimento Econômico (OCDE) (2012), a alfabetização financeira é uma combinação de consciência, conhecimento, habilidade, atitude e comportamento, elementos necessários para tomar as decisões financeiras e, finalmente, alcançar o bem-estar financeiro individual. Já a educação financeira, conforme a Estratégia Nacional de Educação Financeira (ENEF), consiste no processo pelo qual consumidores e investidores melhoram sua compreensão sobre produtos, conceitos e riscos financeiros, obtêm informações e desenvolvem habilidades e confiança, fazendo escolhas mais conscientes e adotando ações para melhorar seu bem -estar (BRASIL, 2010).

Com base no estudo de Huston (2010), é possível afirmar que, além de possuir conhecimento financeiro ou educação financeira, para que um indivíduo seja considerado financeiramente alfabetizado, ele deve saber aplicar esse conhecimento na tomada de decisões financeiras. Nessa mesma linha, Shockey e Seiling (2004) afirmam que somente o conhecimento financeiro não é suficiente para promover mudanças no comportamento, sendo necessário o desenvolvimento de ações que propiciem ao indivíduo tomar decisões financeiras acertadas.

Nesse contexto, é possível compreender que a alfabetização financeira possui duas dimensões: o entendimento, que se refere ao conhecimento fi- nanceiro pessoal (também chamado de educação financeira), e sua utilização, que consiste na aplicação dos conhecimentos na gestão das finanças pessoais (DONADIO et al., 2012). Em outras palavras, o foco principal da educação financeira é o conhecimento, enquanto que a alfabetização financeira envolve, além do conhecimento, a habilidade, o comportamento e a atitude financeira dos indivíduos (PARABONI et al., 2013; POTRICH et al., 2013).

\subsubsection{Comportamento financeiro}

Conforme Ferreira (2008, p. 154), comportamento significa a "maneira de se comportar; procedimento, conduta, ato". Já financeiro, segundo o mesmo autor (2008), é um adjetivo relativo a finanças e à gestão do dinheiro. Diante disso, leva é possível definir comportamento financeiro como a conduta relacionada à gestão do dinheiro.

Embora o comportamento seja mais estudado na área da psicologia, vem crescendo a demanda por pesquisas que busquem identificar o comportamento humano em determinadas decisões, como, por exemplo, nas decisões financeiras (HERLING et al., 2014). Com isso, as finanças comportamentais, que fundam conceitos de economia, finanças e psicologia cognitiva, buscam construir um modelo mais detalhado do comportamento humano nas decisões financeiras, considerando a ideia de que os indivíduos estão sujeitos a fatores comportamentais que muitas vezes os afastam de uma decisão centrada na racionalidade (MACEDO Jr., 2003; LUCENA et al., 2011).

Em relação à mensuração do comportamento financeiro, Matta (2007) elaborou um questionário, com base no instrumento FL-ABK (financial literacy - attitude - behavior - knowledge), utilizado por Susan Shockey (2002), para medir o comportamento financeiro dos universitários do Distrito Federal. Nesse instrumento, são considerados quatro fatores para o comportamento financeiro: 
(I) gestão financeira pessoal; (II) utilização do crédito; (III) investimento e poupança; e (IV) consumo planejado.

O primeiro fator, gestão financeira pessoal, refere-se à gestão dos gastos pessoais, ao comprometimento da renda e ao controle das despesas cotidianas. $\mathrm{O}$ segundo, denominado de utilização do crédito, refere-se ao modo como a renda é complementada e o motivo pelo qual existe essa necessidade, com foco na utilização do cartão de crédito. $\mathrm{O}$ terceiro fator do comportamento financeiro investimento e poupança - refere-se ao modo como a parcela não utilizada da renda é empregada e com qual objetivo. E o quarto e último fator, consumo planejado, diz respeito ao comportamento em relação ao consumo de bens ou serviços de valor significativo.

Nesse sentido, o comportamento financeiro está intimamente ligado ao conceito de educação financeira, uma vez que diversos estudos apontam que o nível de conhecimento financeiro adquirido influencia a qualidade das decisões financeiras (LUCCI et al., 2006; AMADEU, 2009; VIEIRA et al., 2009).

\subsubsection{Conhecimento financeiro}

Sendo o conhecimento financeiro o foco principal da educação financeira (PARABONI et al., 2013; POTRICH et al., 2013), as definições, os estudos e as ações relacionadas à educação financeira têm em seu cerne a forma de adquirir conhecimento financeiro. Partindo desse pressuposto, Amadeu (2009) expõe que a educação financeira pode ser entendida como um processo de construção de conhecimento, que permite aos indivíduos aprimorar sua capacidade financeira a fim de tomar decisões fundamentadas e seguras, dotados de uma postura proativa na busca de seus objetivos.

Devido à evolução dos mercados e dos produtos financeiros, a OCDE recomenda a implantação de programas e estratégias nacionais que proporcionem conhecimento financeiro à popu- lação (SAITO et al., 2006). Embora o Brasil não seja membro da OCDE, ele adota diretrizes e normativas alinhadas às suas práticas (MATSUMOTO et al., 2013), de modo que a educação financeira no país assumiu, em 2010, o papel de política de Estado, por meio da criação da Estratégia Nacional de Educação Financeira (ENEF).

Entre setembro e novembro de 2013, foi realizado um mapeamento das iniciativas de gerar conhecimento financeiro no país. Essa pesquisa deu origem a um documento intitulado "Mapa da Educação Financeira no Brasil: uma análise das iniciativas existentes e as oportunidades para disseminar o tema em todo o país" e identificou quatro segmentos atuantes na educação financeira nacional: i) educação financeira para o futuro, representando $31 \%$ das iniciativas cadastradas e com o objetivo de sensibilizar crianças e adolescentes para o tema; ii) democratização da educação financeira, representando $25 \%$ das iniciativas cadastradas e de caráter gratuito e democrático, sem distinção de público-alvo; iii) consultorias especializadas, representando $24 \%$ das iniciativas e com a finalidade de proporcionar conhecimento financeiro para outras pessoas e organizações na forma de treinamentos e cursos pagos; iv) empresas privadas com foco no mercado de atuação, representando $20 \%$ das iniciativas e com o objetivo de qualificar seus mercados de atuação e atender seus clientes e demais stakeholders (BRASIL, 2014). Como principal conclusão, o relatório mostrou que jovens e adultos com ensino médio e superior são os mais beneficiados por essas iniciativas e que públicos mais vulneráveis a conflitos de consumo, como idosos, crianças e moradores de regiões menos assistidas por órgãos de defesa do consumidor, carecem de ações específicas de educação financeira (BRASIL, 2014).

Em suma, a busca por conhecimento financeiro vem sendo cada vez mais necessária, não somente para pro- 
porcionar qualidade de vida às famílias, mas também para garantir o bom funcionamento dos mercados financeiros e da economia (PARABONI et al., 2013).

\subsection{Estudos sobre o tema}

A alfabetização financeira tem sido amplamente discutida internacionalmente por autores como Lusardi e Mitchell (2007, 2008, 2009, 2014), que pesquisaram diferenças de alfabetização financeira entre homens e mulheres e entre pessoas em diferentes fases da vida, a influência do tema no planejamento da aposentadoria e outras questões relevantes; Lusardi, Schneider e Tufano (2011), que estudaram a fragilidade financeira das famílias americanas; Rooij, Lusardi e Alessie (2011), que encontraram uma forte correlação entre conhecimento financeiro e planejamento da aposentadoria na Holanda; e Huston (2010), que buscou identificar e sintetizar as formas de mensuração da alfabetização financeira.

Contudo, pouco se encontra na literatura brasileira sobre o assunto. Como poucos autores tentaram diferenciar os termos educação e alfabetização financeira, são escassos os estudos, principalmente brasileiros, que tratam do tema. A maioria das pesquisas desenvolvidas no Brasil é caracterizada por discutir a relevância da educação financeira para a sociedade e por avaliar estudantes universitários em relação ao tema.

Entre os estudos brasileiros relativos à educação financeira, destaca-se o estudo de Matta (2007), que investigou o alinhamento entre a oferta de informação sobre finanças pessoais disponibilizadas pelo Programa de Educação Financeira do Banco Central do Brasil (PEF-BC) e a demanda dos universitários do Distrito Federal por essa informação, bem como o comportamento financeiro destes. A grande contribuição dessa pesquisa foi, além de identificar um alinhamento parcial da oferta com a demanda de informações financeiras, mostrar quais temas deveriam ser abordados. Matta (2007) foi um dos primeiros pesquisadores brasileiros a desenvolver, com base em estudos internacionais, um instrumento de pesquisa de comportamento financeiro, que veio a ser utilizado em diversos trabalhos posteriores.

O estudo de Araújo e Souza (2012) comprovou a relevância social do tema, buscando evidenciar que, para cumprir a missão do Banco Central do Brasil, é necessário que o órgão atue na melhoria da educação financeira da sociedade, e constatou, ainda, a contribuição dessas ações ao desenvolvimento socioeconômico sustentável do Brasil.

Outro estudo relevante na área foi o de Amadeu (2009), que pesquisou 587 estudantes universitários dos cursos de Administração, Ciências Contábeis e Matemática da Universidade Estadual do Norte do Paraná (UENP) e comprovou a influência positiva do conhecimento sobre finanças, aprendido em disciplinas específicas ou relacionadas, na tomada de decisões financeiras.

$\mathrm{Na}$ mesma linha de pesquisa, o estudo desenvolvido por Vieira e colaboradores (2009) corroborou o estudo de Amadeu (2009) ao analisar 610 alunos de graduação dos cursos de Administração, Ciências Econômicas e Ciências Contábeis de uma universidade pública do norte do Paraná e constatar que a formação acadêmica contribui para a melhor tomada de decisões de consumo, investimento e poupança. Contudo, os autores ressaltam que existem outras fontes de conhecimento que são também relevantes, como a experiência prática e a família.

No que se refere à alfabetização financeira, um dos pioneiros no Brasil foi o estudo de Donadio e colaboradores (2012), que realizou uma revisão teórica sobre a importância que o acesso ao cartão de crédito e o nível de alfabetização financeira têm no endividamento do consumidor brasileiro.

É importante destacar, ainda, os estudos de Paraboni et al. (2013), Po- 
trich, Vieira e Paraboni (2013), Potrich, Vieira e Ceretta (2013), que foram os primeiros estudos brasileiros que investigaram, por meio de dois ou três fatores, a alfabetização financeira dos estudantes universitários e comprovaram a influência das variáveis demográficas e socioeconômicas no nível de alfabetização financeira.

Além disso, as pesquisas mostraram que os universitários não apresentam níveis desejados de alfabetização financeira, tendo em vista o comportamento financeiro mediano e, principalmente, os níveis insatisfatórios de conhecimento e compreensão de questões financeiras (PARABONI et al., 2013; POTRICH, VIEIRA, PARABONI, 2013; POTRICH, VIEIRA, CERETTA, 2013).

\section{Método}

Este estudo se caracterizou como um survey de abordagem quantitativa e corte transversal. A população pesquisada consiste nos estudantes universitários pertencentes à URCAMP - campus de São Gabriel, Rio Grande do Sul. A amostra foi composta pelos estudantes universitários concluintes, ou seja, com mais de $75 \%$ do curso concluído, uma vez que esses estudantes têm maior possibilidade de completar sua formação e estão prestes a iniciar sua carreira profissional. Além disso, de acordo com Lusardi e Mitchell (2007), quanto maior o nível de educação geral do indivíduo, melhor será seu desempenho nas questões financeiras.

Como instrumento para mensuração do objeto de estudo, optou-se pela utilização de duas proxies, seguindo o procedimento adotado por diversos pesquisadores (KNOLL, HOUTS, 2002; SHIM et al., 2009, SHIM et al., 2010; AKTINSON, MESSY, 2012 apud PARABONI, et al., 2013), os quais, via de regra, avaliaram a alfabetização financeira por meio de uma ou duas proxies. Neste estudo, o comportamento financeiro e o conhecimento financeiro foram definidos como proxies da alfabetização financeira.

Para mensurar o comportamento financeiro mantido pelos estudantes universitários, foi utilizada a escala proposta por Matta (2007), desenvolvida com base em estudos internacionais e composta de 20 questões, organizadas em uma escala do tipo likert de 4 pontos e constituída da seguinte forma: (1) nunca, (2) quase nunca, (3) quase sempre e (4) sempre. Inicialmente, nessa proxy foi realizado o método estatístico multivariado da Análise Fatorial Exploratória (AFE), que visa sintetizar as informações de um grande número de variáveis em um número muito menor de fatores (HAIR et al., 2005), por meio do software SPSS 22.0®. A partir da construção dos fatores, foi realizada uma média aritmética ponderada dos mesmos para cada respondente, seguida de uma média aritmética simples, com o objetivo de classificá-los como detentores de: comportamento financeiro ruim (média dos fatores inferior à 2), comportamento financeiro regular (média dos fatores entre 2 e 3 ) e comportamento financeiro bom (média dos fatores acima de 3), conforme procedimento adaptado de Matta (2007). A figura 1, exposta a seguir, apresenta o modo como foram realizados os cálculos das médias aritméticas ponderada e simples. 


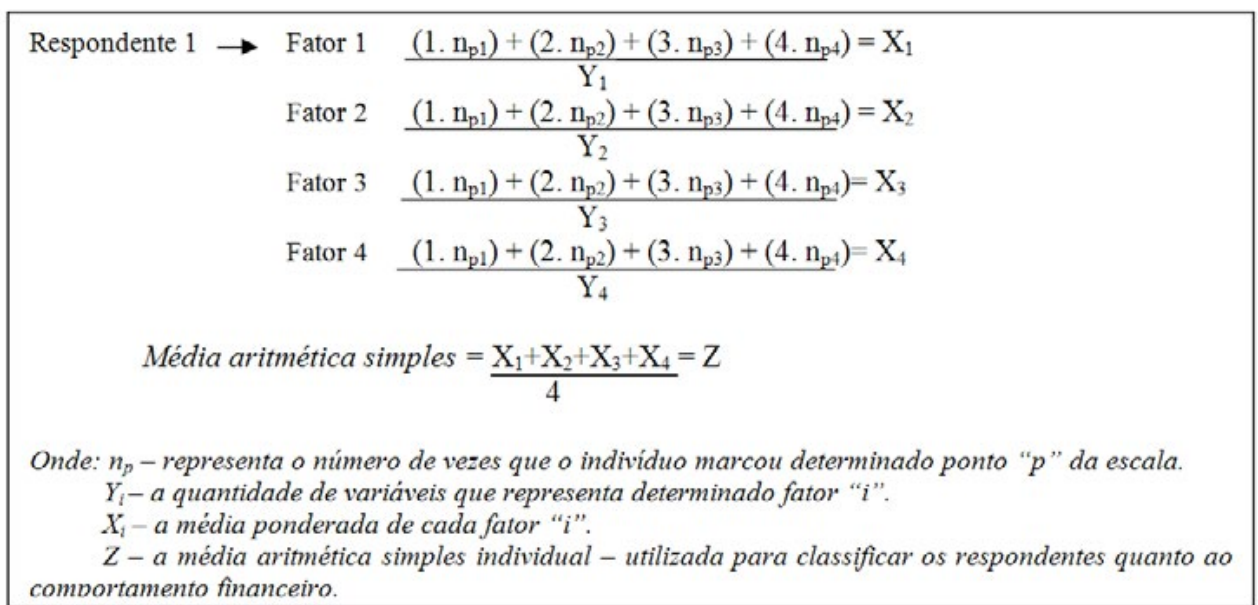

Figura 1 - Cálculo da média aritmética ponderada dos fatores de comportamento financeiro Fonte: elaborado pelos autores.

Para avaliar o conhecimento financeiro dos estudantes universitários, adaptou-se o instrumento de pesquisa desenvolvido por Rooij, Lusardi e Alessie (2011), baseando-se em quatro questões relativas aos juros compostos, à inflação, ao valor do dinheiro no tempo e à ilusão do dinheiro, às quais foi atribuído o valor de 2,5 para cada questão. Ou seja, os estudantes que acertaram todas as questões tiveram uma pontuação igual a 10.

De acordo com a pontuação obti$\mathrm{da}$, os respondentes foram classificados quanto ao desempenho nas questões de conhecimento financeiro da seguinte forma: baixo desempenho (pontuação inferior à 5), desempenho mediano (pontuação entre 5 e inferior a 7,5) e alto desempenho (igual/superior à 7,5 pontos), conforme procedimento adaptado de Potrich, Vieira e Paraboni (2013).

O quadro 1 apresenta as proxies utilizadas para medir a alfabetização financeira e suas respectivas variáveis, bem como as referências e o método de análise utilizado.

\begin{tabular}{|c|c|c|c|}
\hline Proxies & Variáveis & $\begin{array}{c}\text { Técnica Estatís- } \\
\text { tica }\end{array}$ & Referência \\
\hline \multirow{4}{*}{$\begin{array}{l}\text { Comportamento } \\
\text { financeiro }\end{array}$} & Gestão financeira pessoal & \multirow{4}{*}{$\begin{array}{c}\text { Análise Fatorial } \\
\text { Exploratória (AFE) }\end{array}$} & \multirow{4}{*}{ Matta (2007) } \\
\hline & Utilização do crédito & & \\
\hline & Investimento e poupança & & \\
\hline & Consumo planejado & & \\
\hline \multirow{4}{*}{$\begin{array}{l}\text { Conhecimento } \\
\text { financeiro }\end{array}$} & Juros compostos & \multirow{4}{*}{$\begin{array}{l}\text { Estatísticas descri- } \\
\text { tivas }\end{array}$} & \multirow{4}{*}{$\begin{array}{l}\text { Rooij, Lusardi e } \\
\text { Alessie (2011) }\end{array}$} \\
\hline & Inflação & & \\
\hline & Valor do dinheiro no tempo & & \\
\hline & Ilusão do dinheiro & & \\
\hline
\end{tabular}

Quadro 1 - Proxies e suas respectivas variáveis, técnica estatística e referência utilizada Fonte: elaborado pelos autores.

Com base no desempenho apresentado em relação ao comportamento e ao conhecimento financeiros, os estudantes pesquisados foram classificados como detentores de um nível insatisfatório, mediano ou satisfatório de alfabeti- zação financeira, conforme procedimento adaptado de Paraboni et al. (2013).

A coleta de dados foi realizada entre os dias 6 e 13 de outubro de 2014, nos cursos de Administração, Ciências Contábeis, Direito e Educação Física 
da URCAMP - campus de São Gabriel, Rio Grande do Sul.

\section{Apresentação e discussão dos resul- tados}

A pesquisa foi realizada com os estudantes universitários pertencentes à URCAMP - campus de São Gabriel, Rio Grande do Sul, sendo a amostra final composta de 126 estudantes. Evidencia-se que os cursos que tiveram a maior contribuição para a constituição da amostra foram Direito $(39,7 \%)$ e Administração $(33,3 \%)$, representando, juntos, $73 \%$ dos respondentes. Já o curso de Ciências Contábeis representou $18,3 \%$ da amostra, enquanto que o curso de Educação Física representou $8,7 \%$.

Quanto ao perfil dos respondentes, verificou-se que a maior parcela é constituída de mulheres $(60,3 \%)$, tem entre 21 e 29 anos $(60,3 \%)$ e é solteira $(62,7 \%)$. A maioria dos estudantes pesquisados é independente financeiramente $(54,8 \%)$, com renda mensal entre $\mathrm{R} \$ 501,00$ e $\mathrm{R} \$ 2.000,00$ (68,2\%).

Após o conhecimento do perfil dos respondentes, passou-se para a construção dos fatores relativos ao comportamento financeiro por meio da realização de uma AFE. Quanto ao método de rotação, foi utilizado o procedimento Varimax. Para verificar a adequação da utilização da AFE, aplicaram-se os tes- tes de Kaiser-Meyer-Olkin (KMO) e de esfericidade de Bartlett. O KMO mede a adequação dos dados, de modo que os valores devem ser maiores que 0,6 , indicando que a realização da análise fatorial é satisfatória devido à forte correlação entre as variáveis (LATIF, 1994). Já o teste de esfericidade de Bartlett, por sua vez, visa avaliar a hipótese de as variáveis não serem correlacionadas na população, ou seja, de não haver correlação perfeita entre as variáveis (LOESCH; HOELTGEBAUM, 2012).

Partindo dessas premissas, os resultados dos testes foram satisfatórios: o KMO apresentou um coeficiente de 0,783, e o teste de Bartlett apresentou resultado significativo (valor 839,085; sig.0,000), indicando a adequação da análise fatorial. Em seguida, partiu-se para a análise das comunalidades. Após essa análise, não foi retirada nenhuma das variáveis, pois todas alcançaram valores superiores a 0,5 (HAIR et al., 2005).

Na sequência, para a determinação do número de fatores e das questões correspondentes a cada um, utilizou-se o critério dos autovalores, que representa a quantidade de variância nas variáveis originais que está associada a um fator, considerando-se apenas variáveis com valor acima de 1,0 (HAIR et al., 2005). A Tabela 1 , a seguir, apresenta os resultados para os fatores.

Tabela 1 - Variância total explicada

\begin{tabular}{c|c|c|c}
\hline \multirow{2}{*}{ Componente } & \multicolumn{3}{|c}{ Valores próprios iniciais } \\
\cline { 2 - 4 } & Total & \% de variância & \% cumulativa \\
\hline 1 & 5,433 & 27,164 & 27,164 \\
\hline 2 & 2,023 & 10,117 & 37,281 \\
\hline 3 & 1,617 & 8,084 & 45,365 \\
\hline 4 & 1,474 & 7,372 & 52,737 \\
\hline 5 & 1,223 & 6,114 & 58,851 \\
\hline 6 & 1,030 & 5,148 & 63,999 \\
\hline
\end{tabular}

Fonte: elaborada pelos autores. 
Inicialmente, foram constatados seis fatores com uma variância acumulada de $63,99 \%$. No entanto, para a análise final, restaram apenas quatro fatores, pois, os fatores 4 e 5 foram retirados, uma vez que ficaram com apenas uma variável cada. Na sequência, realizouse novamente o teste de $\mathrm{KMO}$, o qual reproduziu um coeficiente de 0,73 , ratificando a adequação da AFE. A seguir, apresentam-se os fatores restantes com suas respectivas variáveis na Tabela 2 .

Tabela 2 - Fatores do comportamento financeiro

\begin{tabular}{|c|c|c|c|c|}
\hline & \multicolumn{4}{|c|}{ Fatores } \\
\hline & 1 & 2 & 3 & 6 \\
\hline $\begin{array}{l}\text { o) Poupa visando à compra de um produto mais caro } \\
\text { (ex.: carro, casa)? }\end{array}$ & \multirow{3}{*}{$\begin{array}{l}, 841 \\
, 691 \\
673\end{array}$} & \multirow{9}{*}{,777 } & \multirow{9}{*}{$\begin{array}{r}, 718 \\
, 569\end{array}$} & \\
\hline n) Poupa mensalmente? & & & & \\
\hline $\begin{array}{l}\text { p) Possui uma reserva financeira maior ou igual a } 3 \\
\text { vezes a sua renda mensal, que possa ser usada em casos } \\
\text { inesperados (ex.: desemprego, doença)? }\end{array}$ & & & & \\
\hline $\begin{array}{l}\text { d) Segue um orçamento ou plano de gastos semanal } \\
\text { ou mensal? }\end{array}$ & & & & \\
\hline $\begin{array}{l}\text { e) Fica mais de um mês sem fazer o balanço dos seus } \\
\text { gastos? }\end{array}$ & & & & \\
\hline s) Compra por impulso? & & & & \\
\hline $\begin{array}{l}\text { r) Analisa suas finanças com profundidade antes de fa- } \\
\text { zer alguma grande compra? }\end{array}$ & & & & \\
\hline $\begin{array}{l}\text { 1) Paga integralmente a fatura do(s) seu(s) cartão(ões) } \\
\text { de crédito a fim de evitar encargos financeiros (juros e } \\
\text { multas)? }\end{array}$ & & & & ,807 \\
\hline $\begin{array}{l}\text { m) Confere a fatura dos cartões de crédito para averi- } \\
\text { guar erros e cobranças indevidas? }\end{array}$ & & & & ,698 \\
\hline
\end{tabular}

Fonte: elaborada pelos autores.

Embora existam algumas divergências nas variáveis levantadas, os fatores encontrados corroboram a pesquisa de Matta (2007), que identificou quatro fatores que explicam o comportamento financeiro - neste estudo, optou-se por seguir a nomenclatura utilizada por Matta (2007). Portanto, o primeiro fator, denominado de "Investimento e Poupança", é composto de três questões relacionadas à prática de poupar e aplicar recursos financeiros. $\mathrm{O}$ segundo fator, definido como "gestão financeira pessoal", refere-se a questões relacionadas ao controle e planejamento dos gastos. $\mathrm{O}$ terceiro fator, composto de questões relacionadas ao comportamento de compra, é denominado "consumo planejado". Por fim, o quarto fator, relacionado à forma de financiamento das compras, foi denominado de "utilização do crédito".

Logo após a determinação dos fatores, procedeu-se à análise das estatísticas descritivas a fim de identificar a média dos fatores e classificar os respondentes quanto ao comportamento financeiro, conforme explicado na seção do método, em que comportamento financeiro ruim é representado por uma média dos fatores inferior à 2 ; comportamento financeiro regular é definido por uma média dos fatores entre 2 e 3; e comportamento financeiro bom é constituído por uma média acima de 3 , seguindo procedimento adaptado de Matta (2007). Os resultados estão apresentados na Tabela 3, exposta a seguir. 
Tabela 3 - Avaliação do comportamento financeiro dos estudantes pesquisados

\begin{tabular}{cccccc}
\hline $\begin{array}{c}\text { Classificação do } \\
\text { comportamento } \\
\text { financeiro }\end{array}$ & $\begin{array}{c}\text { Investimen- } \\
\text { to e poupan- } \\
\text { ça }\end{array}$ & $\begin{array}{c}\text { Gestão } \\
\text { financeira } \\
\text { pessoal }\end{array}$ & $\begin{array}{c}\text { Consu- } \\
\text { mo pla- } \\
\text { nejado }\end{array}$ & $\begin{array}{c}\text { Utiliza- } \\
\text { ção do } \\
\text { crédito }\end{array}$ & $\begin{array}{c}\text { Média do com- } \\
\text { portamento } \\
\text { financeiro }\end{array}$ \\
\hline Ruim & $24,60 \%$ & $15,90 \%$ & $4,80 \%$ & $6,30 \%$ & $12,90 \%$ \\
Regular & $37,30 \%$ & $38,10 \%$ & $21,40 \%$ & $17,50 \%$ & $28,58 \%$ \\
Bom & $38,10 \%$ & $46,00 \%$ & $73,80 \%$ & $76,20 \%$ & $58,53 \%$ \\
\hline TOTAL & $100 \%$ & $100 \%$ & $100 \%$ & $100 \%$ & $100 \%$ \\
\hline
\end{tabular}

Fonte: elaborada pelos autores.

Com base na Tabela 3, constatase, de modo geral, que mais da metade dos respondentes $(58,53 \%)$ apresentam um comportamento financeiro bom, principalmente devido aos fatores "consumo planejado" e "utilização do crédito", em que, respectivamente, $73,80 \%$ e $76,20 \%$ dos estudantes apresentaram média acima de 3 , uma vez que a escala variou entre 1 e 4 . O resultado encontrado corrobora os estudos de Potrich, Vieira e Paraboni (2013) e Potrich, Vieira e Ceretta (2013), que identificaram como adequado o comportamento financeiro dos estudantes universitários de diferentes universidades públicas e privadas de Santa Maria, Rio Grande do Sul.
Na sequência, foi analisado o conhecimento financeiro dos estudantes com base no instrumento de pesquisa proposto por Rooij, Lusardi e Alessie (2011), por meio de quatro questões, às quais foi atribuído o valor de 2,5 para cada questão. Ou seja, os estudantes que acertaram todas as questões obtiveram pontuação igual a 10. Dessa forma, foi possível verificar o desempenho dos estudantes pesquisados em relação a cada variável, sendo "ilusão do dinheiro" e "inflação" as variáveis com o maior número de acertos, conforme mostra a Tabela 4.

Tabela 4 - Desempenho dos estudantes para cada variável do conhecimento financeiro

\begin{tabular}{ccc}
\hline Variáveis & Quantidade de acertos & Percentual de acertos \\
\hline Juros compostos & 54 & $42,86 \%$ \\
Inflação & 56 & $44,44 \%$ \\
Valor do dinheiro no tempo & 48 & $38,10 \%$ \\
Ilusão do dinheiro & 74 & $58,73 \%$ \\
\hline
\end{tabular}

Fonte: elaborada pelos autores.

Esse resultado está em consonância com o encontrado por Rooij, Lusardi e Alessie (2011), que identificaram o bom desempenho por parte das famílias holandesas no que se refere à "inflação" e à "ilusão do dinheiro", que aparecem entre as três variáveis com maior número de acertos. Já em pesquisas com estudantes universitários, essa constatação também aparece no estudo de Potrich, Vieira e Paraboni (2013), que encontraram um bom nível de acertos na questão referente à inflação, mostrando que os estudantes universitários santa-marienses detêm um bom conhecimento sobre esse assunto.
Após analisar o desempenho obtido em relação a cada variável, foi avaliada a pontuação final de cada respondente, os quais foram classificados quanto ao desempenho nas questões de conhecimento financeiro da seguinte forma: baixo desempenho (pontuação inferior à 5), desempenho mediano (pontuação entre 5 e 7,4) e alto desempenho (igual/superior a 7,5 pontos), conforme procedimento adaptado de Potrich, Vieira e Paraboni (2013), como mostra a Tabela 5. 
Tabela 5 - Avaliação do conhecimento financeiro dos estudantes pesquisados

\begin{tabular}{ccc}
\hline $\begin{array}{c}\text { Desempenho no conhecimento } \\
\text { financeiro }\end{array}$ & $\begin{array}{c}\text { Quantidade de respon- } \\
\text { dentes }\end{array}$ & $\%$ desempenho \\
\hline Baixo & 47 & $37,30 \%$ \\
Mediano & 40 & $31,75 \%$ \\
Alto & 39 & $30,95 \%$ \\
\hline Total & 126 & $100,00 \%$ \\
\hline
\end{tabular}

Fonte: elaborada pelos autores.

Com base na Tabela 5, é possível constatar que o desempenho apresentado pelos estudantes pesquisados se equiparou nos três patamares, com um pequeno destaque para o baixo desempenho $(37,3 \%)$. O resultado encontrado assemelha-se às conclusões de diversos estudos, como Paraboni et al. (2013), Matta (2007), Rooij, Lusardi e Alessie (2011), Potrich, Vieira e Paraboni (2013) e Potrich, Vieira e Ceretta (2013), ao constatar que a maioria dos estudantes apresenta baixo desempenho em relação ao conhecimento financeiro.

Por fim, foi avaliado o nível de alfabetização financeira dos estudantes universitários da URCAMP com base no desempenho apresentado em relação ao comportamento e ao conhecimento financeiros, conforme procedimento adaptado de Paraboni et al. (2013). Verificou-se, assim, que os estudantes pesquisados, de modo geral, apresentam um nível de alfabetização financeira mediano, devido ao bom comportamento financeiro e ao equiparado desempenho nas questões de conhecimento financeiro.

O nível de alfabetização financeira encontrado neste estudo está de acordo com as pesquisas de Matta (2007), Paraboni et al. (2013), Potrich, Vieira e Paraboni (2013) e Potrich, Vieira e Ceretta (2013), uma vez que estes pesquisadores identificaram um nível mediano de alfabetização financeira dos universitários e aquém do ideal para estudantes de nível superior.

\section{Considerações finais}

O objetivo do presente estudo foi verificar se os estudantes universitários da URCAMP de São Gabriel, Rio Grande do Sul, são alfabetizados financeiramente, por meio da mensuração do comportamento e conhecimento financeiros. Para isso, inicialmente foi identificado o perfil dos 126 respondentes, sendo os cursos de Direito e Administração os mais frequentados pelos estudantes pesquisados, que, em sua maioria, são mulheres $(60,3 \%)$, na faixa etária de 21 a 29 anos $(60,3 \%)$, solteiros $(62,7 \%)$ e independentes financeiramente $(54,8 \%)$, com renda mensal entre $\mathrm{R} \$ 501,00$ e $\mathrm{R} \$ 2.000,00(68,2 \%)$.

Para avaliar o nível de alfabetização financeira dos respondentes, foram utilizadas duas proxies: comportamento financeiro e conhecimento financeiro. $\mathrm{O}$ comportamento financeiro foi mensurado por meio do instrumento de pesquisa desenvolvido por Matta (2007), com base em estudos internacionais. Para a análise dos dados, foi realizada uma $\mathrm{AFE}$ e, na sequência, a análise das estatísticas descritivas a fim de identificar a média dos fatores e avaliar o comportamento financeiro dos estudantes.

Por meio da AFE, foram identificados quatro fatores: investimento e poupança; gestão financeira pessoal; consumo planejado; e utilização do crédito, destacando-se com melhor desempenho as questões relativas ao "consumo planejado" e à "utilização do crédito", o que demonstra que os estudantes pesquisados se preocupam em comprar de forma consciente e honrar os compromissos assumidos. 
Com base nas estatísticas descritivas dos fatores, os estudantes foram classificados de acordo com a média obtida como detentores de um comportamento financeiro ruim, regular ou bom, conforme procedimento adaptado de Matta (2007). Desse modo, concluiuse que, de maneira geral, os estudantes apresentam um bom comportamento financeiro, corroborando os resultados do estudo de Potrich, Vieira e Ceretta (2013), que identificaram um comportamento financeiro positivo nos estudantes universitários da região central do Rio Grande do Sul.

Em seguida, procedeu-se à análise do conhecimento financeiro dos estudantes com base no instrumento de pesquisa proposto por Rooij, Lusardi e Alessie (2011), destacando-se o desempenho dos estudantes nas questões relacionadas à "inflação" e "ilusão do dinheiro", que obtiveram maior número de acertos.

Com base na pontuação final, os respondentes foram classificados quanto ao desempenho nas questões de conhecimento financeiro do seguinte modo: baixo, mediano ou alto desempenho, seguindo procedimento adaptado de Potrich, Vieira e Paraboni (2013). De modo geral, o desempenho apresentado pelos estudantes pesquisados equiparou-se nos três níveis de conhecimento, com um pequeno destaque para o baixo desempenho $(37,3 \%)$. O resultado encontrado não é exclusividade desta pesquisa, uma vez que o baixo desempenho em questões relativas a finanças também foi encontrado nos estudos de Matta (2007), Rooij, Lusardi e Alessie (2011), Paraboni et al. (2013), Potrich, Vieira e Paraboni (2013) e Potrich, Vieira e Ceretta (2013).

Por fim, foi possível verificar que os estudantes pesquisados apresentam, de modo geral, um nível de alfabetização financeira mediano, uma vez que, embora tenham apresentado, em sua maioria $(58,53 \%)$, um bom comportamento financeiro, o desempenho em relação ao conhecimento financeiro foi insuficiente para considerar a amostra com um nível satisfatório de alfabetização financeira, pois a maior parte $(37,3 \%)$ dos pesquisados apresentou baixo nível de conhecimento financeiro.

$\mathrm{O}$ fato de os estudantes terem apresentado um bom comportamento financeiro, frente ao pequeno destaque ao baixo desempenho nas questões de conhecimento financeiro, pode ser explicado devido à experiência prática ou a ensinamentos da família, fatores que estão presentes no comportamento do indivíduo de forma empírica, conforme ressaltam Amadeu (2009) e Vieira et al. (2009).

Entretanto, também não é possível avaliar os respondentes como detentores de um nível insatisfatório de alfabetização financeira, pois, se avaliados os patamares de desempenho mediano e alto de conhecimento financeiro juntos, estes somam $62,7 \%$ da amostra, corroborando as pesquisas de Amadeu (2009) e Vieira et al. (2009), ao constatar a influência do conhecimento financeiro nas decisões financeiras. Esse resultado está de acordo com os estudos de Matta (2007), Paraboni et al. (2013), Potrich, Vieira e Paraboni (2013) e Potrich, Vieira e Ceretta (2013), ao identificar um nível mediano de alfabetização financeira dos universitários e aquém do ideal para estudantes de nível superior.

Esta pesquisa teve algumas limitações, como o fato de abranger apenas uma instituição de ensino superior. Além disso, o conhecimento financeiro foi analisado somente por meio de quatro questões, cada uma representado um assunto, como o "valor do dinheiro no tempo", por exemplo, que poderia ter sido mais explorado com o auxílio de outras questões. Entretanto, é importante destacar que são poucos os estudos no Brasil que abordam o tema da alfabetização financeira, sendo esta pesquisa mais uma contribuição para o assunto.

Além disso, a principal contribuição deste estudo foi evidenciar uma 
lacuna, não apenas no ensino superior, mas também no processo educacional como um todo, uma vez que estudantes universitários concluintes, pertencentes a cursos distintos, apresentaram dificuldades em relação a questões relativas ao conhecimento financeiro. As ações desenvolvidas no Brasil para a difusão da cultura pela busca de conhecimento financeiro são muito recentes e, embora estejam avançando em alguns pontos, ainda estão engatinhando em meio à evolução dos mercados, uma vez que, mesmo com a implantação da ENEF, não há perspectiva de, em um futuro próximo, inserir a educação financeira como disciplina obrigatória na matriz curricular em nenhum dos níveis educacionais (BRASIL, 2014a).

Devido à importância da alfabetização financeira na carreira profissional e na vida pessoal dos indivíduos, sugere-se para pesquisas futuras investigar as ações desenvolvidas para o fomento da alfabetização financeira (além da educação financeira) no país ou em determinada região, bem como estudar o tema em populações diferentes, como estudantes de ensino médio/técnico ou colaboradores de certa empresa a fim de investigar a influência do tema no ambiente de trabalho.

\section{Referências}

1. AMADEU, J. R. A educação financeira e sua influência nas decisões de consumo e investimento: proposta de inserção da disciplina na matriz curricular. 2009. 92 f. Dissertação (Mestrado em Educação) - Universidade do Oeste Paulista, Presidente Prudente.

2. ARAÚJO, F. de A. L.; SOUZA, M. A. P. de. Educação Financeira para um Brasil Sustentável: Evidências da necessidade de atuação do Banco Central do Brasil em educação financeira para o cumprimento de sua missão. In: Trabalhos para Discussão, n. 280, 2012, Brasília. Jun./2012.
3. BRASIL. Decreto-lei $\mathbf{n}^{\mathbf{0}} \mathbf{7 3 9 7}$, de 22 de dezembro de 2010. Institui a Estratégia Nacional de Educação Financeira - ENEF, dispõe sobre a sua gestão e dá outras providências. Diário Oficial da República Federativa do Brasil, Brasília, DF, 22 dez. 2010.

4. . Mapa da Educação Financeira no Brasil: uma análise das iniciativas existentes e as oportunidades para disseminar o tema em todo o País. Disponível em <www.vidaedinheiro.gov. br> Acesso em 20 mai. 2014.

5.

Plano Diretor ENEF Anexo 4: orientação para educação financeira nas escolas. Disponível em $<$ www.vidaedinheiro.gov.br $>$ Acesso em 27 jul. 2014a.

6. BRESSER-PEREIRA, L. C. Desenvolvimento e crise no Brasil: história, economia e política de Getúlio Vargas a Lula. Rio de Janeiro: Editora 34, 2003.

7. DONADIO, R.; CAMPANARIO, M. de A.; RANGEL, A. de S. O papel da alfabetização financeira e do cartão de crédito no endividamento dos consumidores brasileiros. ReMark - Revista Brasileira de Marketing. São Paulo, v.11, n.1, p 75-93, jan./abr. 2012.

8. FERREIRA, A. B. de H. Aurélio: o dicionário da língua portuguesa. Curitiba: Ed. Positivo, 2008. 544 p.

9. HAIR JR., J. F. et al. Fundamentos de Métodos de Pesquisa em Administração. Tradução: Lene Belon Ribeiro. Porto Alegre: Bookman, 2005.

10. HERLING, L. H. D.; et al. Finanças Corporativas: sua organização e base epistemológica. Revista de Ciências da Administração, v. 16, n. 39, p. 179193, agosto 2014.

11. HUSTON, S. J. Measuring financial literacy. The Journal of Consumer Affairs, v. 44, n. 2, p. 296-316, 2010.

12. LATIF, S. A. A Análise Fatorial auxiliando a resolução de um problema real de pesquisa de marketing. Caderno de pesquisas em Administração, 1994, v. 00, n. 0, jul. 1994. 
13. LEAL, A. E. M.; SOUZA, C. E. G. de. Construindo o conhecimento pela pesquisa: orientação básica para a elaboração de trabalhos científicos. Santa Maria: Sociedade Vicente Pallotti, 2006.

14. LOESCH, C.; HOELTGEBAUM, M. Métodos estatísticos multivariados. São Paulo: Saraiva, 2012.

15. LUCCI, C. R.; et al. A Influência da Educação Financeira nas Decisões de Consumo e Investimento dos Indivíduos. In: IX Seminários em Administração, 2006, São Paulo. IX SEMEAD FEA-USP, 2006.

16. LUCENA, W. G. L.; et al. Finanças Comportamentais: fatores que influenciam os consumidores na hora da compra. Revista Estudos do CEPE, Santa Cruz do Sul, n. 33, p. 93-126, jan/jun 2011.

17. LUSARDI, A.; MITCHELL, O. Baby Boomer Retirement Security: The Role of Planning, Financial Literacy and Housing Wealth. Journal of Monetary Economics, 54, p. 205-224. 2007.

18. Planning and Financial Literacy: How Do Women Fare? American Economic Review. 2008.

19. How Ordinary Consumers Make Complex Economic Decisions: Financial Literacy and Retirement. National Bureau of Economic Research. 2009.

20. The economic importance of Financial Literacy: theory and evidence. Journal of Economic Literature, vol LII, March 2014.

21. LUSARDI, A.; SCHNEIDER, D.; TUFANO, P. Financially fragile households: evidence and implications. Brookings papers on economic activity. Spring, 2011.

22. MACEDO Jr., J. S. Teoria do Prospecto: uma investigação utilizando simulação de investimentos. 2003. 218 f. Tese (Doutorado em Engenharia da
Produção) - Universidade Federal de Santa Catarina, Florianópolis.

23. MATSUMOTO, A. S. et al. Educação financeira: estudo comparativo entre estudantes de uma Universidade pública (PR) e uma privada (DF). In: XII Seminários em Administração, 2013, São Paulo. XVI SEMEAD FEA -USP, 2013.

24. MATTA, R. O. B. Oferta e demanda de informação financeira pessoal: o Programa de Educação Financeira do Banco Central do Brasil e os universitários do Distrito Federal. 2007. $214 \mathrm{f}$. Dissertação de Mestrado (Mestrado em Ciência da Informação) - Universidade de Brasília, Brasília.

25. ORGANIZAÇÃO PARA A COOPERAÇÃO ECONÔMICA E DESENVOLVIMENTO (OECD). Improving financial literacy: analysis of issues and policies, 2012. Disponível em: $<\mathrm{f}$ tp://ftp.fsb.co.za/public/Consumer $\% 20$ Education/Presentations/2009\%20Improving_Financial_\%20Literacy.pdf $>$. Acesso em: 07 abr. 2014.

26. PARABONI, A. L.; et al. Alfabetização financeira dos estudantes universitários: construção de um indicador e a influência das variáveis demográficas e socioeconômicas. In: XXVI ENANGRAD. Florianópolis, set./out. 2013.

27. POTRICH, A. C. G.; VIEIRA, K. M.; PARABONI, A. L. O que influencia a alfabetização financeira dos estudantes universitários? In: XII Seminários em Administração, 2013, São Paulo. XVI SEMEAD FEA-USP, 2013.

28. POTRICH, A. C. G.; VIEIRA, K. M.; CERETTA, P. S. Nível de Alfabetização Financeira dos estudantes universitários: afinal, o que é relevante? RECADM - Revista Eletrônica de Ciência Administrativa. Campo Largo, nov. 2013.

29. ROOIJ, M. C. J. V.; LUSARDI, A.; ALESSIE, R. J. M. Financial literacy and retirement planning in the Nether- 
lands. Journal of Economic Psychology, v. 32, n. 4, p. 593-608, 2011.

30. SAITO, A. T.; SAVOIA, J. R. F.; PETRONI, L. M. A educação financeira no Brasil sob a ótica da Organização de Cooperação e de Desenvolvimento Econômico (OCDE). In: IX Seminários em Administração, 2006, São Paulo. IX SEMEAD FEA-USP, 2006.

31. SHOCKEY, S. S. Low-wealth adults financial literacy: Money management behavior and associates factors, including critical thinking. Tese, Universidade de Utah, Estados Unidos, 2002.

32. SHOCKEY, S. S.; SEILING, S. B. Moving into action: application of the transtheoretical model of behavior change to financial education. Financial Planning and Counseling, 2004.

33. VIEIRA, S. F. A.; et al. Educação financeira e decisões de consumo, investimento e poupança: uma análise dos alunos de uma universidade pública do Paraná. In: XII Seminários em Administração, 2009, São Paulo. XII SEMEAD FEA-USP, 2009. 